\title{
Checkmating the Weaknesses Associated with Information and Communication Technologies in Education for Improved Effectiveness and Efficiency
}

\author{
Johnson, Idorenyin Edet ${ }^{1} \quad$ Nkanu, Celestine Unoh ${ }^{1} \quad$ Udo, Agnes Lambert ${ }^{2 *}$ \\ 1.Department of Curriculum and Teaching (Edu-Tech Unit), Faculty of Education, University of Calabar, \\ Calabar, Cross River State, Nigeria \\ 2.Department of Curriculum and Teaching, School of Education, College of Education, Afaha Nsit, Akwa Ibom
} State, Nigeria

\begin{abstract}
Information and Communication Technologies (ICTs) have been identified as having two sides like a coin when used instructionally. While some scholars insist on the need to always prepare and deliver instructions using ICTs, others express worries over the pedagogical weaknesses thereof. This paper therefore $\mathrm{x}$-rays the instructional strengths of ICTs to include; improving educational quality, enhancing access to education, easing collaboration, motivating learning, provision of remote learning resources, enhancing technological literacy, amongst others. It further enumerates the weaknesses of ICTs in teaching and learning to include high cost of acquiring and maintaining infrastructure and equipment, creation of inequality among learners, causing distraction among learners, encouraging cheating in examination and during assignments, exposing learners to technological hazards, inter alia. The paper proffers recommendations on how to effectively engage ICTs in teaching - learning to maximize the potentials, amongst which are: adequate funding for ICT sector in every educational institution; identification of needs, goals and objectives; proper budgeting and planning; engaging stakeholders for awareness and getting their inputs; ensuring safe and conducive environmental setting for the equipment; carrying out periodic employment, training and re-training of man-power; putting in place robust plagiarism software to checkmate theft of intellectual property; and providing detailed orientation for learners who are the end-users of the ICTs in the classrooms.
\end{abstract}

Keywords: Checkmating, Weaknesses, ICTs, Effectiveness, Efficiency.

DOI: $10.7176 / \mathrm{JEP} / 12-8-11$

Publication date:March $31^{\text {st }} 2021$

\section{Introduction}

In our world today, the extent of technological involvement in any sphere of human endeavor is proportionally commensurate with the ease of executing complex tasks with less stress and uttermost effectiveness and efficiency in those areas. This is evident in ' $e$ ' attached to commerce, banking, amongst others; which connote the involvement of technology. In the field of education, technology has been integrated to, not only the classroom or formal education, but all aspects of the entire educational sector.

Technology is possibly the strongest factor influencing the educational system today. The use of technology in the educational system has, over the years, greatly enhanced the knowledge base of the teachers and their students alike, as well as diversified the ways instructional contents are prepared and delivered to the learners. Integrating technology with standard curriculum goes beyond giving students a sense of control to allowing for advanced learning of broad topics through wide spectrum of information platforms (Takasi, 2019)

In the context of education, "technology" connotes Information and Communication Technologies (ICTs) that are useful in the educational system for effective educational management and instructional delivery. ICTs are different sets of technological tools and resources available for designing, creating, storing, reproducing, transmitting and managing information effectively and efficiently (Mangal and Mangal, 2004). They also include the hardware devices and associated software which are powered by electricity, solar energy or battery.

Inyang-Abia (2014) posits that ICTs have created a 'global village square' where people can communicate with others across the world as if they are in the confine of the same room. Our society today is so engraved to technology that almost every aspect of our daily lives utilize technology in one form or the other. Ushie and Akpan (2018) add that ICTs, especially the computer and internet technologies in education, when properly utilized, enhance new ways of learning, rather than allow teachers and students keep repeating what they have done in the same old ways.

The use of technology for instructional delivery has, over the years, been consistently emphasized by education scholars, with empirical and theoretical evidences of the strength thereof. Bearing in mind that technology, like a coin, has two sides, this paper seeks to point out the strengths of ICTs in education, X-ray the weaknesses thereof and recommend replicable ways of managing the weaknesses for improved effectiveness and efficiency. 


\section{Strengths of Information and Communication Technologies in Education}

ICTs have proven to be both transformational and problem solving tools in the field of education. When appropriately engaged in education, the following strengths are evident:

\subsection{Improving Access to Education:}

With the use of computer and internet, mobile technology, radio, television and social media, the margin of educational exclusively has been significantly reduced. Kidzo (2008) observes that it is difficult to quantify the degree to which ICTs have helped expand access to education. ICTs have also enabled distance education's effectiveness by providing necessary tools and resources for effective management and instructional delivery.

\subsection{Enhancing Educational Quality}

Kidzo (2008) comments that the impact of educational radio, television and other ICT enabled broadcasts on the quality of education, across various levels, still remains an under-researched area. He adds that the little research data available prove that ICT based interventions are more effective and efficient than traditional classroom talk and chalk methods. Using ICTs to prepare and deliver multimedia lessons, engaging social media and mobile technologies as well as publishing on wikis, websites and blogs have significantly improved on information access thereby improving the quality of education. Developing educational systems have been able to model after developed ones using appropriate ICTs.

\subsection{Extending Educational Opportunities}

Elvis (2009) considers ICTs as potentially powerful tool for extending educational opportunities to previously neglected people such as scattered and rural populations and groups traditionally excluded from education due to cultural or social reasons, gender, age, disability, cost and time constraint.

\subsection{Easing Collaboration:}

With the use of ICTs, scholars across the world can hold meetings, share ideas and work together effectively to carry out academic tasks and proffer solutions to various problems, without seeing physically or meeting in a physical location. This eliminates the barrier of time, cost of transportation and distance among scholars wishing to work together from across different places. The use of Language Translating Software Applications (LTSA) also helps to eliminate language barriers in scholarly collaborations.

\subsection{Motivating Learning}

ICTs such as videos, television, radio and multimedia computer software that combine text, sound, colour and animation can be used to provide challenging instructional contents that will effectively engage the learners and ensure maximal achievement of instructional objectives (Eze, 2006). ICTs combine the media dynamism, interactivity and connectivity to instructionally engage real people in real time.

\subsection{Provision of Remote Learning Resources}

Mangal and Mangal (2004) note that with the Internet and the World Wide Web, a wealth of learning materials in every subject matter and across varieties of media can be accessed by anyone from just anywhere. This makes it possible for teachers and learners to access other materials different from the usual printed and other hard copy media.

\subsection{Improving Basic Skills Acquisition}

Through drill and practice as well as repetition and reinforcement, the foundation of higher order thinking skills and creativity, which is basic skill and concept, get facilitated through ICTs. The elementary learners who are exposed to educational videos and other multi-media packages tend to do much better than their counterparts who are not (Tonio, 2014).

\subsection{Enhancing Technological Literacy}

By making learners interact with various ICTs to learn, it facilitates their technological literacy and ability to function effectively in a technology driven society. 21st century skills which include functional literacy, visional literacy, scientific literacy, technological literacy, information literacy, cultural literacy, global awareness (digital age literacy), inventive thinking, higher order thinking and sound reasoning, effective communication and high productivity; are inculcated in the learner (Kidzo, 2008).

\subsection{Facilitating Individualized and Group Learning}

Because of the ability of ICTs to defy time and location, it makes it possible for learners to access information and carry out individual and group tasks with other learners from different geographical locations at their own time. 
Through instructional radio, television, internet platforms and mobile applications, learners can access instructions from different places at different times, either individually or in groups, without seeing the teacher physically.

\subsection{Encouraging Effective Teacher Training and Creativity}

Modern ICTs have made it possible for teachers to be trained at the level of global best practice for teaching and learning. Many bodies and professional individuals have also made various materials available online that will help the teachers overcome instructional challenges of any kind. Also, the need to prepare and deliver instructions via ICTs place a demand on the teacher for self-development and creativity.

\subsection{Helping Challenged Learners}

ICTs, when appropriately utilized instructionally could meet the learning needs of learners with varying disabilities and bridge the gaps between the learners. The use of various technology-based learning aids for varying learning needs as emphasized by the Federal Government of Nigeria in National Policy on Education (2014) makes for effective inclusive education where various learners with varying abilities, challenges and learning styles learn together effectively without leaving any behind.

\subsection{Enhancing Effective Documentation}

Using the computer and internet cloud- computing allows for creating database and saving information in a way that can be easily accessed but incorruptible. This makes for effective management of student's progress report, continuous assessment, and examination scores. Such information get saved even for future use. ICTs also enhance effective documentation of every information within a given educational system.

While it is impossible to deny the potentiality of ICTs when appropriately utilized for educational purposes, it will be unscholarly to ignore the other side thereof; as the strengths may not be fully realized if the weaknesses are not well managed.

\section{Weaknesses of Information and Communication Technologies in Education}

Like a coin, ICTs, when used educationally, have the good and unpleasant sides. Therefore, having outlined the positive side, it will be judicious to outline the negative sides which are as follows:

\subsection{High-Cost Implication}

The cost of acquiring and maintaining instructional gadgets, preparing conducive environments for utilizing them as well as employing and training manpower is highly exorbitant and not many schools can afford it. Those that can afford such facilities have corresponding high tuition fees, which makes it unaffordable to low- and mediumincome earning parents to enroll their wards. Due to the cost implication also, ICTs meant for education are seen as being meant for the rich only.

\subsection{Creation of Inequality Amongst Teachers and Learners}

Apart from having money to afford the gadgets, manpower and environment, technological literacy is required amongst teachers and learners for effective instructional use of ICTs. Peter (2009) asserts that seven out of every ten teachers lack the technological literacy to manipulate ICTs for effective instructional delivery. Where the teachers are found wanting, even the students become helpless and the gap of inequality continues to widen between teachers and students. Teachers' inexperience in preparing, presenting and evaluating instructional exercises using ICTs makes for inequality amongst both the learners and the teachers. It is also true that learners don't have equal access to ICTs, and where they even have, devices' variability is inevitable.

\subsection{Causing Distractions Amongst Learners}

Using mobile gadgets with internet connection can cause serious distractions among learners. In some cases, when unsupervised, learners tend to abandon the learning tasks to go out browsing sites that are totally unconnected with learning tasks, and even engage in seeing videos and chatting with friends on social media platforms. This causes a lot of distractions to the learners.

\subsection{Encouraging Cheating on Assignments and Examinations}

Even though it is on record that lazy students always look for a way to engage in different forms of cheating, mobile gadgetry with Internet connection makes it possible to copy from varieties of published works online to do assignments. During examinations, some students sneak into examination halls with mobile technologies they can copy from. These hamper effective development of learners.

\subsection{Encouraging Information Recycling}

Noticeably, even among scholars, new researches are hardly embarked upon because technology makes it easy to 
readily lay hands on information to copy and paste, with little or no additional contributions. This situation hampers scholarship from reaching its full potentials. Also, it avails researchers of unverified information as everyone is at liberty to upload any information online without proper verification.

\subsection{Stressing to Plan and Deliver Instructions and Evaluate with}

Asides the technological literacy and creativity required of teachers in the instructional use of ICTs, it is very stressful to plan, design, produce, utilize and evaluate instructional packages effectively. The time factor and stress involved in using ICTs for instruction also serve as discouraging factors.

\subsection{Putting Emphases on Technology above Teachers}

At the heart of ICTs is the idea of making learners acquire learning with little or no involvement of the teachers. Many scholars show worries about this, arguing that technology is not safe without adequate presence of teacher to guide such usage and ensure instructional compliance.

\subsection{Exposing Learners to Hazards}

Since ICTs majorly require the learners to look into the screen (projection, computer or mobile gadgets' screens), opticians have raised concerns that continuous looking into the screen by learner could have both short and long term effects on their sights. Toholi (2018) notes that students who interact with ICTs to learn suffer much more optical challenges than their counterparts who don't interact with ICTs. Some students have also experienced electric shocks in the course of learning with technological gadgets.

\subsection{Crippling Learners' Ability to Think Critically}

With the use of calculator and other brain supporting technologies, learners tend to rely more on getting quick answers instead of racking their brains and this plays down on the learners' power of critical thinking. Also, having every information readily available on the net hamper critical reasoning amongst learners and researchers (Singh, 2008).

\subsection{Non-Protection of Intellectual Property}

Many great ideas and scholarly findings made available online are accessed and utilized without any credence to the originator. In many cases, even acknowledgement is denied as the copier tends to claim ownership of the idea. This is more so because there are no standardized modalities for ensuring the protection of intellectual property of scholars.

Seeing that these weaknesses are inherent in ICTs, but do not overrule the potentialities thereof, it therefore becomes needful to proffer ways of mitigating the issues while harnessing its instructional potentialities.

\section{Recommendations for Managing the Weaknesses of ICTs in Instructional Delivery.}

The problems associated with the instructional utilization of ICTs can be effectively managed to the end and the intended goals and objectives realized, if the following approaches are adopted keenly:

\subsection{Identify the Needs, Goals and Objectives}

The adoption of ICTs in schools must never be done haphazardly or in a rush. The government or school management must carry out a proper need assessment to establish the rationale for embarking on such project for the school. Based on that, goals should be clearly stated and broken down into realizable objectives. It is upon this that the decision to proceed or withdraw will be reached.

\subsection{Planning a Budget and Possible Funding}

A detailed budget must be drawn, taking into consideration the equipment/infrastructure, internet connections, man-power, power supply and everything that will be needed. For this task, the government or school management must engage a professional ICT firm to study their goals and objectives and, based on their affordability, prepare an effective budget. Money should be provided to finance the prepared budget.

\subsection{Engage the Stakeholders}

While planning, the government or school management should engage the teachers, learners, parents and guardians to make their own observation about the project. They should be given adequate briefing on the need for such project and the role each of them would have to play in the realization of laid down objectives. Every question, reservations and fears should be adequately entertained to clear every doubt and ensure their cooperation.

\subsection{Arrange the Environment}

To begin the project, after money is made available based on the prepared budget, the hall, sitting arrangement, 
lighting, ventilation and power supply must be arranged for. If there is an already existing hall, other things should be fixed as considered necessary; but if there is no existing facility for such project, a good space could be chosen for the building to be fixed. With other specifications, every infrastructure and support must be in place.

\subsection{Employ, Train and Retrain Manpower}

While the fixing of the infrastructure is ongoing, necessary manpower, such as teachers, content designers and developers, technicians and administrators should be employed, trained and retrained by the government and school management on the design, planning, utilization and evaluation of instructions using ICTs. Teachers, especially, should be given special attention as they are the bridge between learners and ICTs. Apart from being trained on preparation, utilization and evaluation, teachers must be trained on how to supervise and manage the learners who use ICTs to learn to ensure that distractions are reduced to the barest minimum.

\subsection{Acquire, Install and Maintain the Equipment}

As earlier specified in the budget, every equipment should be acquired, installed and maintained by the school management, with the help of specialized manpower. Alternative power supply must be in place. Also, regular check of the hardware must be ensured and replacement of malfunctioning components done. Internet connection must always be available for the hardware resources that require such, and regular software updates must be taken care of to ensure optimum efficiency of the hardware. This will ensure sustainability.

\subsection{Provide Orientation for the Learners}

Before any kind of interaction with the gadgets, the learners should be given cautionary orientation about the usage of such gadgets. Safe handling and damage prevention should be taken seriously. Above all, the learners should be made to understand that the essence of the entire set-up of ICTs is for improved learning only and nothing else. Disciplinary measures should be taken against any erring learner.

\subsection{Pursue the Objectives Religiously}

The teachers should pursue the objectives of such projects by ensuring that learners engage in learning tasks under strict supervision. They should use the ICTs to prepare, present and evaluate their instructional contents to an extent considered needful. They should adhere to the precautions associated with such use and encourage the learners to do same to avoid associated hazards.

\subsection{Understand the Challenges and Mitigate on Time}

Various learners may experience various challenges which may be physical or psychological. Teachers should work with parents to take care of any challenge that a learner may face to ensure that every learner derives maximum instructional benefits from ICTs. Challenges like fire outbreak, electric shock and accidents must be anticipated by the planners, and mitigation measures should be put in place as well.

Conclusively, the potentials of educational use of ICTs are great, but may not be effectively achieved if the weaknesses are not given careful consideration in their usages. Therefore, the outlined recommendation, if strictly adhered to, will ensure the effective realization of the potentials of the use ICTs in schools, while ensuring that the weaknesses are effectively mitigated.

\section{References}

Eze, F. E. (2006). Fundamentals of information and communication technologies in education. Lagos: Galaxy Publishers.

Federal Government of Nigeria (2014). National Policy on Education (6 ${ }^{\text {th }}$ Ed). Abuja: National Educational Research \& Development Council (NERDC)

Inyang-Abia, M. E. (2014). Clouds in the light kingdom: Reboot the curriculum. University of Calabar $60^{\text {th }}$ Inaugural Lecture, Calabar: University of Calabar Printing Press.

John, S. A. (2012). Information and communication technologies: An emerging diversified trend. Port Harcourt: Galaxy Publishers.

Kidzo, Y. C. (2008) The Integration of technology in the 21 st century classroom: Attitudes and pedagogical beliefs toward emerging technologies. Journal of Technology Integration in the Classroom, 5 (1): 6 - 14.

Mangal, S. K. \& Mangal, U. (2010). Essential of educational technology. New Delhi: PHI Learning Private Limited.

Peter, P. R. (2019). Information and communication technology in education: The theory and practice. Retrieved from https:/www.edu.issues.icttp.article.41

Singh, T. K. (2008). Instructional technology in education. New Delhi: A.P.H. Publishing Corporation.

Takasi, N. T. (2019). Technology integration in teaching and learning. Journal of Teaching and Teacher Education, $24(6), 1316-1326$ 
Tinio, P. L. (2014). Educational information and communication technologies. Retrieved from http:/www.en.m.wikibooks.com

Toholi, M. I. (2018). Learning with information and communication technologies: An emerging pedagogy. New York: Green House Publishers.

Ushie, B. C. \& Akpan, S. J. (2018). New perspectives in Integrating technology into instruction.

Calabar: University of Calabar Printing Press. 